\title{
Determinants of levels and changes of physical functioning in chronically ill persons: results from the GLOBE Study
}

\author{
J P Mackenbach, G J J M Borsboom, W J Nusselder, C W N Looman, C T M Schrijvers
}

\begin{abstract}
Study objective-Declines in physical functioning are a common result of chronic illness, but relatively little is known about factors not directly related to severity of disease that influence the occurrence of disability among chronically ill persons. The aim of this study was to assess the effect of a large number of potential determinants (sociodemographic factors, health related behaviour, structural living conditions, and psychosocial factors).

Design-Longitudinal study of levels and changes of physical functioning among persons suffering from four chronic diseases (asthma/chronic obstructive pulmonary disease (COPD), heart disease, diabetes, chronic low back pain). In 1991, persons suffering from one or more of these diseases were identified in a general population survey. Self reported disabilities, using a subset of the OECD disability indicator, were measured six times between 1991 and 1997. These data were analysed using generalised estimating equations, relating determinants measured in 1991 to disability between 1991 and 1997, and controlling for a number of potential confounders (age, gender, year of measurement, and type and severity of chronic disease).
\end{abstract}

Setting-Region of Eindhoven (south eastern Netherlands).

Participants-1784 persons with asthmal COPD, heart disease, diabetes mellitus and/or low back pain.

Main results-In a "repeated prevalence" model, statistically significant $(p<0.05)$ and strong associations were found between most of the determinants and the prevalence of disabilities. In a "longitudinal change" model, statistically significant $(p<0.05)$ predictors of unfavourable changes in physical functioning were low income and excessive alcohol consumption, while we also found indications for effects of marital status, degree of urbanisation, smoking, and external locus of control.

Conclusions-Other factors than characteristics of the underlying disease have an important influence on levels and changes of physical functioning among chronically ill persons. Reduction of the prevalence of disabilities in the population not only depends on medical interventions, but may also require social interventions, health education, and psychological interventions among chronically ill persons. (F Epidemiol Community Health 2001;55:631-638)

The compression of morbidity hypothesis suggests that it may be possible to reduce cumulative lifetime morbidity, while maintaining or even further increasing total life expectancy. ${ }^{1}$ This requires a reduction of the burden of chronic morbidity, either by reducing the incidence of chronic diseases, through primary or secondary prevention efforts, or by limiting the losses of physical functioning and other consequences that often accompany chronic diseases. Although prevention of chronic diseases may be preferable from a public health point of view, current prospects for total elimination of chronic diseases are mostly unrealistic, and the second approach therefore is certainly also needed.

How to reduce the losses of physical functioning that often accompany chronic diseases? Here again, one should perhaps first look at opportunities for preventing such losses, by identifying determinants of physical disabilities among chronically ill persons and by acting on those determinants. Relatively little is known, however, about such determinants. Previous studies have suggested that, in addition to age and aspects of chronic disease itself (for example, type and severity), a number of "extraneous" factors may also play a part. This includes sociodemographic variables like gender, race, marital status and socioeconomic status ${ }^{2-10}$; behaviour related determinants like smoking, physical exercise, obesity and alcohol consumption ${ }^{5-8}{ }^{11-13}$; and psychosocial factors like social support and self efficacy. ${ }^{514}$ Results of previous studies are, however, inconsistent and have not always been adequately controlled for presence and severity of chronic diseases.

In this paper we report on a populationbased study, in which we explored possible determinants of levels and changes of physical functioning among persons suffering from one or more of four specific chronic diseases (asthma/chronic obstructive pulmonary disease (COPD), heart disease, diabetes mellitus, low back pain). We looked at a wide range of possible determinants and controlled for presence and severity of chronic disease at baseline. In addition to the three groups of variables mentioned above (sociodemographic variables, health related behaviours, and psychosocial factors) we also looked at "structural living 
Table 1 Number of participants approached and not approached in each study year; number of non-respondents and respondents of those approached each study year; number of respondents with missing data and number in analyses of OECD score

\begin{tabular}{llllllll}
\hline Year & Total & $\begin{array}{l}\text { Not approached } \\
\text { (\% death) }\end{array}$ & Approached & Non-respondents & Respondents & Missing data (\%) & $\begin{array}{l}\text { Number in } \\
\text { analyses } \neq\end{array}$ \\
\hline 1991 & 1784 & - & 1784 & - & 1784 & $141(7.9)$ & 1643 \\
1992 & 1784 & $86(19)$ & 1698 & 189 & 1509 & $134(8.9)$ & 1375 \\
1993 & 1784 & $165(29)$ & 1619 & 227 & 1392 & $103(7.4)$ & 1289 \\
1994 & 1784 & $233(32)$ & 1551 & 206 & 1345 & $100(7.4)$ & 1245 \\
1995 & 1784 & $292(34)$ & 1492 & 247 & 1245 & $82(6.6)$ & 1163 \\
1997 & 1784 & $356(44)$ & 1428 & 161 & 1267 & $97(7.7)$ & 1170
\end{tabular}

*Initial participants could not be approached again to participate for any of the following reasons: (1) mortality; (2) explicit refusal to further participate in the study; (3) emigration; (4) loss to follow up. $†$ Number approached = total number minus number not approached. $\ddagger$ Number in analyses $=$ number of respondents minus number with missing data.

conditions", such as housing and working conditions and financial problems. The reason for including this set of variables was that one consistent finding from previous studies is that socioeconomic status is an important predictor of disabilities. The effect of socioeconomic status on disabilities is likely to be attributable at least in part to structural living conditions, but it is unknown which specific factors are involved.

\section{Methods}

POPULATION

We used data from the GLOBE study, which is the Dutch acronym for "Health and Living Conditions of the Population of Eindhoven and surroundings". ${ }^{15}$ The study started in 1991 with a baseline measurement consisting of a postal survey and an oral interview. The postal survey was sent to a random sample of 27070 inhabitants (15-74 years) of the city of Eindhoven and 17 surrounding municipalities. The response rate of the postal survey was $70.1 \%(n=18$ 973). About five months later, an oral interview was held among a sample of 3968 persons drawn from respondents to the postal survey. To increase the power of the study, people who reported one or more of the following chronic diseases were overrepresented in this sample: asthma/COPD, heart disease, diabetes mellitus, and severe low back complaints. These diseases were overrepresented because they are fairly common, and cover a wide range of possible consequences of disease. The response rate was $72.3 \%$, resulting in 2867 respondents. For the analyses presented in this paper, respondents suffering from at least one of the four chronic diseases were selected. This selection resulted in a sample size of 1784 respondents in 1991.

Between 1992 and 1995, follow up data were collected by a postal survey, while in 1997 the data collection consisted of a postal survey and an interview. Each study year, the respondents to the 1991 questionnaire who suffered from one or more of the four chronic diseases $(n=1784)$, were asked to participate again, unless one of the following events had occurred: mortality (total number of events $(\mathrm{n})=$ 155); refusal to further participate in the study $(n=181)$, emigration $(n=7)$, lost to follow up $(n=13)$. Table 1 contains, for each study year, the number of people approached and the number not approached, the number of respondents and non-respondents, the number of respondents with missing data on disability, and the resulting number of observations included in the analyses.

\section{DATA}

Disabilities were measured by responses to the Organization for Economic Cooperation and Development (OECD) Long-term Disability Questionnaire. ${ }^{16}$ The OECD indicator measures physical functioning with a specific focus on the aspects of self care, mobility, and communication. In this study, we used a modified eight item version (see appendix), which was based on factor analysis of the OECD items in a Dutch sample ${ }^{17}$ and was mainly restricted to aspects of mobility and communication. The respondent was asked with how much effort a specific task could be done; possible answers were: (1) with no effort, (2) with some effort, (3) with a lot of effort, (4) I cannot do this. A total score was calculated, in which the separate answers were counted according to this ranking (for example, "no effort" $=1$ and "I cannot do this"=4). Thus, the total score for the eight items potentially ranged between 8 (no disabilities) and 32 ("I cannot do this" for all eight tasks). In 1991, the OECD indicator was part of the oral interview, while in subsequent years (yearly between 1992 and 1995 and then again in 1997) it was part of a postal survey. Because the focus of the analysis was on differences between subgroups in levels and changes of disability, bias attributable to differences in method of administration between the first and the other five measurements is very unlikely.

The presence of four specific chronic diseases was measured in 1991 by using disease specific questionnaires on asthma/COPD,${ }^{18}$ heart disease, ${ }^{19} 20$ diabetes mellitus, ${ }^{21}$ and severe low back complaints. ${ }^{22}{ }^{23}$ Information from these questionnaires was used to assign each respondent to a specific category of a disease, indicating severity, including a category of respondents that did not suffer from the specific disease. For asthma/COPD, five categories were distinguished: (1) no asthma/ COPD; (2, 3 and 4) three categories indicating increasing severity of the disease (asthma/ COPD grade 1, 2 and 3); and (5) other forms of asthma/COPD. ${ }^{18}$ For heart disease the following six categories were distinguished: (1) no heart disease; (2) non-specific symptoms; (3) angina pectoris without heart failure; (4) heart failure without angina pectoris; (5) angina pectoris with heart failure; (6) other 
forms of heart disease. ${ }^{19}{ }^{20}$ Four categories of the diabetes variable were distinguished: (1) no diabetes; (2) diabetes without complications; (3) diabetes with at least one complication; (4) other forms of diabetes. ${ }^{21}$ Finally, seven categories of low back pain were distinguished: (1) no complaints; (2) complaints in upper part back/ shoulder(s); (3) low back pain, no radiation, less than three months; (4) low back pain, with radiation, less than three months; (5) low back pain, no radiation, at least three months; (6) low back pain, with radiation, at least three months; (7) other forms of back complaints. $^{22}$ Numbers of respondents with at least some degree of suffering from each of these conditions were as follows: asthma/ COPD 708, heart disease 969, diabetes mellitus 253, and low back pain 1103. Many respondents suffered from more than one condition.

In addition to the presence of chronic diseases self reports on a wide range of possible determinants of disabilities were elicited in 1991 (number of categories distinguished in the analysis within parentheses):

- sociodemographic variables: age (in years), gender (2), marital status (4), degree of urbanisation (4), level of education (4), occupational class (6), equivalent household income (5)

- lifestyle factors: smoking (5), alcohol consumption (5), leisure time physical exercise (4), body mass index (3)

- structural living conditions: housing conditions (4), neighbourhood conditions (4), physical working conditions (7), job control (7), job demands (5), social support at work (5), financial problems (3), labour market position (7)

- psychosocial factors (all measured as continuous scores, scale lengths given in table with results): long lasting difficulties, seven coping styles, emotional and instrumental social support, neuroticism, locus of control. Fuller descriptions of these variables can be found in another paper. ${ }^{15}$

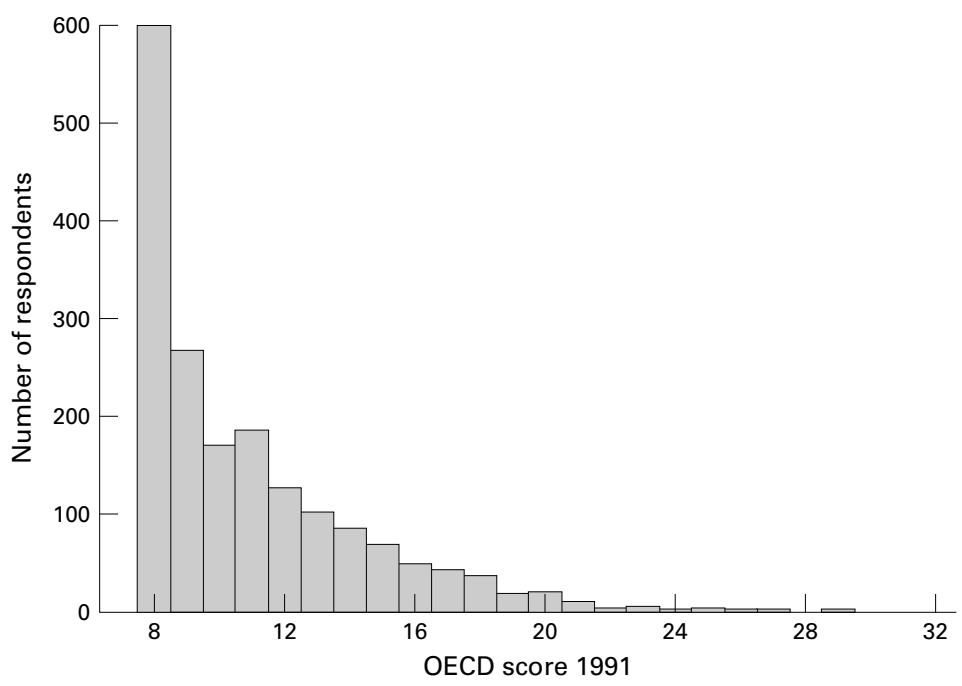

Figure 1 Distribution of the OECD score during the baseline measurement (1991).
ANALYSES

Because we used six repeated measurements of disability, adjustment for within subject correlation was necessary, which was achieved by using the generalised estimating equations (GEE) method. ${ }^{24}$ SAS version 6.12 TS level 0060 was used. Two different models were fitted, each with the (continuous) OECD score as dependent variable.

The first model contained the determinant of interest as well as a number of possible confounders (age, gender and chronic disease by severity category in 1991, and year of measurement). This model was used to study associations between each of the determinants as measured in 1991 and average levels of disability as measured between 1991 and 1997. We will call this the "repeated prevalence" model, because it essentially quantifies the effect of determinants on the prevalence of disability as measured repeatedly, adjusted for dependencies of successive measurements within individuals and adjusted for a common trend with year (that is, changes over time that are common to all participants) and other possible confounders. The parameters of interest are the coefficients for each of the categories of the determinants (indicating the unit difference in average disability level during the whole period 1991-1997, measured on a scale between 8 and 32 , when comparing the category of the determinant to a reference category), their standard errors, as well as the $p$ value for an overall test of statistical significance of the contribution of the determinant to the model (Wald test).

The second model contained all variables of the first model as well as interaction terms between the determinant of interest and year of measurement, between the determinant of interest and age, and between age and year of measurement. This model was used to study associations between each of the determinants and changes in physical functioning. We will call this the "longitudinal change" model, because it quantifies associations between determinants as measured in 1991 and changes in disabilities between 1991 and 1997, adjusted for dependencies of successive measurements within individuals and adjusted for a common trend with year and other possible confounders. The parameters of interest were the coefficients for the interaction terms between year of measurement and each of the categories of the determinants (indicating the unit extra increase in disability level per year, measured on a scale between 8 and 32, when comparing one category of the determinant to a reference category), their standard errors, as well as the $\mathrm{p}$ value for an overall test of statistical significance of the contribution of these interaction terms to the model (Wald test). The interaction between determinant and age was added to the model in order to remove possible confounding due to differences between categories of the determinants in the effects of age (that is, aging). The interaction between age and year of measurement was added to the model in order to remove possible confounding due to differences between age groups in the effects of year 
Table 2 The presence of four chronic diseases: associations with levels and changes of disability

\begin{tabular}{|c|c|c|c|c|c|c|}
\hline & \multicolumn{3}{|c|}{ Repeated prevalence model* } & \multicolumn{3}{|c|}{ Longitudinal change model $t$} \\
\hline & Coefficient & $\begin{array}{l}\text { Standard } \\
\text { error }\end{array}$ & $\begin{array}{l}\text { Overall p } \\
\text { value }\end{array}$ & Coefficient & $\begin{array}{l}\text { Standard } \\
\text { error }\end{array}$ & $\begin{array}{l}\text { Overall } p \\
\text { value }\end{array}$ \\
\hline Asthma/COPD & & & $<0.001$ & & & 0.036 \\
\hline Severeł versus no & 0.922 & 0.258 & & 0.132 & 0.045 & \\
\hline Heart disease & & & $<0.001$ & & & 0.083 \\
\hline Severe $₫$ versus no & 3.014 & 0.476 & & 0.099 & 0.068 & \\
\hline Diabetes mellitus & & & 0.110 & & & 0.002 \\
\hline Severe $\uparrow$ versus no & 1.044 & 0.484 & & 0.281 & 0.076 & \\
\hline Low back pain & & & $<0.001$ & & & 0.653 \\
\hline Severe \| versus no & 2.144 & 0.340 & & -0.029 & 0.052 & \\
\hline
\end{tabular}

*Adjusted for age, gender and other chronic disease by severity category in 1991, and year of measurement (1991-1997). †Adjusted for age, gender and other chronic disease by severity category in 1991, year of measurement (1991-1997), and the interactions between the determinant of interest and age and between age and year of measurement. $¥$ Asthma/COPD grade 3 . $\$$ Angina pectoris with heart failure. $\mid$ Diabetes mellitus with at least one complication. $\|$ Low back pain, with radiation, at least three months.

(that is, trend over time). Without these two interaction terms adjustment for the (longitudinal) effects of age would have been incomplete.

\section{Results}

The prevalence of disabilities in our study population at baseline, indicated by the OECD score, is given in figure 1 . Although the participants were selected on the basis of the presence of chronic disease, about a third reported no disabilities at all (OECD score $=8$ ). The average OECD score was 10.83 in 1991, and 11.01 in 1997.

Before we present the results for each of the groups of determinants, we will first briefly describe the associations between each of the four diseases included in the study and disability (table 2). It is important to note that our study population was limited to persons suffering from at least one of these diseases, and that all analyses are controlled for the presence of (other) chronic diseases. Therefore, the reference categories in table 2 (for example, "no astma/COPD") refer to persons suffering from one of the other conditions, and all associations presented in the table reflect the effect of (disease specific) comorbidity on physical disabilities. In the repeated prevalence model, asthma/ COPD, heart disease and low back pain are statistically significantly $(\mathrm{p}<0.05)$ associated with the presence of physical disabilities, as indicated by the "overall $\mathrm{p}$ values" for the inclusion of these variables to the model. For example, a person having "severe asthma/ COPD" has a 0.922 points higher OECD score, on average during the period 19911997, than a person without asthma/COPD. In the longitudinal change model, asthma/COPD and diabetes mellitus are statistically significantly $(p<0.05)$ associated with changes in physical functioning, while the overall $\mathrm{p}$ value of including heart disease to the model indicates only borderline statistical significance $(\mathrm{p}<0.10)$. The presence of asthma/COPD, heart disease and diabetes goes together with a larger increase in the number and/or severity of disabilities. For example, among persons having "severe asthma/COPD" in 1991 the OECD score increases 0.132 points per year faster than among persons without asthma/COPD.

Table 3 presents the results for the sociodemographic variables. In addition to an overall $\mathrm{p}$ value for the statistical significance of each of the determinants, the table also presents the coefficients for the most informative level of each of the determinants, usually the level indicating the highest exposure to the determinant. In the repeated prevalence model, relatively small effects are seen for gender and degree of urbanisation (coefficients for the "extreme" categories are -0.368 and -0.258 , respectively, implying a 0.368 and 0.258 points lower OECD score than the reference category). Larger effects are seen for marital status, level of education, occupational class and household income (coefficients for the extreme categories range between 1.248 and 1.853). Chronically ill persons who are divorced, have a low level of education, belong to the manual occupational class or have a low household income, have more disabilities than

Table 3 Sociodemographic variables: associations with levels and changes of disability

\begin{tabular}{|c|c|c|c|c|c|c|}
\hline & \multicolumn{3}{|c|}{ Repeated prevalence model* } & \multicolumn{3}{|c|}{ Longitudinal change model $\uparrow$} \\
\hline & Coefficient & $\begin{array}{l}\text { Standard } \\
\text { error }\end{array}$ & $\begin{array}{l}\text { Overall } p \\
\text { value }\end{array}$ & Coefficient & $\begin{array}{l}\text { Standard } \\
\text { error }\end{array}$ & $\begin{array}{l}\text { Overall } p \\
\text { value }\end{array}$ \\
\hline Gender & & & 0.058 & & & 0.796 \\
\hline Male versus female & -0.368 & 0.194 & & 0.007 & 0.028 & \\
\hline Marital status & & & $<0.001$ & & & 0.085 \\
\hline Divorced versus married & 1.816 & 0.595 & & 0.072 & 0.087 & \\
\hline Degree of urbanisation & & & 0.036 & & & 0.056 \\
\hline Rural versus big city & -0.258 & 0.304 & & 0.064 & 0.038 & \\
\hline Level of education & & & $<0.001$ & & & 0.267 \\
\hline Low versus high & 1.477 & 0.282 & & 0.050 & 0.039 & \\
\hline Occupational class & & & 0.003 & & & 0.761 \\
\hline Manual versus professional & 1.248 & 0.357 & & 0.065 & 0.076 & \\
\hline Household income & & & $<0.001$ & & & 0.006 \\
\hline Low versus high & 1.853 & 0.382 & & 0.171 & 0.056 & \\
\hline
\end{tabular}

*Adjusted for age, gender and chronic disease in 1991 by severity category, and year of measurement (1991-1997). †Adjusted for age, gender and chronic disease in 1991 by severity category, year of measurement (1991-1997), and the interactions between the determinant of interest and age and between age and year of measurement. 
Table 4 Health related behaviours: associations with levels and changes of disability

\begin{tabular}{|c|c|c|c|c|c|c|}
\hline & \multicolumn{3}{|c|}{ Repeated prevalence model* } & \multicolumn{3}{|c|}{ Longitudinal change modelt } \\
\hline & Coefficient & $\begin{array}{l}\text { Standard } \\
\text { error }\end{array}$ & $\begin{array}{l}\text { Overall p } \\
\text { value }\end{array}$ & Coefficient & $\begin{array}{l}\text { Standard } \\
\text { error }\end{array}$ & $\begin{array}{l}\text { Overall p } \\
\text { value }\end{array}$ \\
\hline Smoking & & & 0.009 & & & 0.293 \\
\hline$>20 \mathrm{cig} /$ day versus never & 1.404 & 0.436 & & 0.178 & 0.084 & \\
\hline Alcohol consumption & & & $<0.001$ & & & 0.044 \\
\hline Excessive versus moderate & 0.252 & 0.833 & & 0.132 & 0.050 & \\
\hline Physical exercise & & & $<0.001$ & & & 0.788 \\
\hline None versus frequent & 1.985 & 0.480 & & -0.019 & 0.068 & \\
\hline Body Mass Index & & & 0.009 & & & 0.349 \\
\hline Obese versus normal & -0.132 & 0.255 & & 0.037 & 0.037 & \\
\hline
\end{tabular}

*Adjusted for age, gender and chronic disease in 1991 by severity category, and year of measurement (1991-1997). †Adjusted for age, gender and chronic disease in 1991 by severity category, year of measurement (1991-1997), and the interaction between the determinant of interest and age and between age and year of measurement.

chronically ill persons who are married, have a high level of education, belong to the professional occupational class, or have a high household income. In the longitudinal change model, only household income is statistically significantly $(\mathrm{p}<0.05)$ associated with changes in physical functioning, whereas the associations with marital status and degree of urbanisation are only borderline statistically significant $(\mathrm{p}<0.10)$. Among chronically ill persons with a low household income the OECD score increases 0.171 points per year faster than among chronically ill persons with a high household income. The divorced and those living in rural areas also seem to have a less favourable course of physical functioning.

Table 4 presents the results for the health related behaviours. Smoking, alcohol consumption, leisure time physical exercise, and body mass index are all statistically significantly $(p<0.05)$ associated with the prevalence of disabilities in the repeated prevalence model. Chronically ill persons who smoke, drink excessively or are sedentary have higher OECD scores; for body mass index, it is not obesity that is associated with a higher OECD score but a very low body weight (body mass index $<20 \mathrm{~kg} / \mathrm{m}^{2}$; results not shown). In the longitudinal change model, only alcohol consumption is statistically significantly associated with changes in physical functioning: chronically ill persons with excessive alcohol consumption have slightly faster increasing $(0.132$ points per year) OECD scores than persons with moderate alcohol consumption. Although the overall test for smoking does not indicate statistical significance, chronically ill persons who are heavy smokers do have faster increasing $(0.178$ points per year) OECD scores than chronically ill non-smokers.

Table 5 presents the results for structural living conditions. Again, most of the variables are associated with the prevalence of disabilities in the repeated prevalence model. The largest coefficient is seen for financial problems: chronically ill persons with great financial problems have a considerably higher prevalence of disabilities (2.941 points) than chronically ill persons without financial problems. In the longitudinal change model, none of the variables is statistically significantly associated with change in physical functioning. The four work related variables have (non-significant) negative coefficients in this model, suggesting that more unfavourable working conditions are associated with less increase in disabilities.

Table 6 presents the results for the psychosocial variables. Longlasting difficulties, some of the coping styles, (lack of) social support, neuroticism and external locus of control are all statistically significantly associated with a higher prevalence of disabilities. Effect sizes cannot directly be compared with those of the variables discussed before, because the psychosocial factors were included as continuous variables (scale lengths given in table 6). For

Table 5 Structural living conditions: associations with levels and changes of disability

\begin{tabular}{|c|c|c|c|c|c|c|}
\hline & \multicolumn{3}{|c|}{ Repeated prevalence model* } & \multicolumn{3}{|c|}{ Longitudinal change model $\dagger$} \\
\hline & Coefficient & $\begin{array}{l}\text { Standard } \\
\text { error }\end{array}$ & $\begin{array}{l}\text { Overall } p \\
\text { value }\end{array}$ & Coefficient & $\begin{array}{l}\text { Standard } \\
\text { error }\end{array}$ & $\begin{array}{l}\text { Overall } p \\
\text { value }\end{array}$ \\
\hline Housing conditions & & & 0.061 & & & 0.776 \\
\hline Three problems versus none & 0.948 & 0.403 & & 0.061 & 0.083 & \\
\hline Neighbourhood conditions & & & 0.117 & & & 0.953 \\
\hline Three problems versus none & 0.731 & 0.393 & & -0.005 & 0.054 & \\
\hline Physical working conditions & & & 0.004 & & & 0.823 \\
\hline$>$ Five problems versus none & 0.187 & 0.320 & & -0.026 & 0.068 & \\
\hline Job control & & & 0.002 & & & 0.794 \\
\hline Five problems versus none & -0.102 & 0.510 & & -0.100 & 0.109 & \\
\hline Job demands & & & $<0.001$ & & & 0.812 \\
\hline High versus low & -0.186 & 0.443 & & -0.057 & 0.063 & \\
\hline Social support at work & & & 0.018 & & & 0.627 \\
\hline Very little versus much & 0.194 & 0.356 & & -0.037 & 0.067 & \\
\hline Financial problems & & & $<0.001$ & & & 0.680 \\
\hline Great problems versus none & 2.941 & 0.546 & & 0.030 & 0.081 & \\
\hline Position in labour market & & & $<0.001$ & & & 0.632 \\
\hline Unemployed versus paid work & 0.881 & 0.432 & & 0.058 & 0.074 & \\
\hline
\end{tabular}

*Adjusted for age, gender and chronic disease in 1991 by severity category, and year of measurement (1991-1997). †Adjusted for age, gender and chronic disease in 1991 by severity category, year of measurement (1991-1997), and the interactions between the determinant of interest and age and between age and year of measurement. 
Table 6 Psychosocial factors: associations with levels and changes of disability

\begin{tabular}{|c|c|c|c|c|c|c|}
\hline & \multicolumn{3}{|c|}{ Repeated prevalence model* } & \multicolumn{3}{|c|}{ Longitudinal change model $t$} \\
\hline & Coefficient & $\begin{array}{l}\text { Standard } \\
\text { error }\end{array}$ & $\begin{array}{l}\text { Overall } p \\
\text { value }\end{array}$ & Coefficient & $\begin{array}{l}\text { Standard } \\
\text { error }\end{array}$ & $\begin{array}{l}\text { Overall } p \\
\text { value }\end{array}$ \\
\hline & & & $<0.001$ & & & 0.464 \\
\hline Longlasting difficulties $(0-12) \ddagger$ & 0.238 & 0.054 & & 0.005 & 0.007 & \\
\hline Coping: confronting $(8-32) \neq$ & -0.097 & 0.022 & $<0.001$ & 0.004 & 0.004 & 0.319 \\
\hline Coping: depressive $(7-24) \ddagger$ & 0.154 & 0.039 & $<0.001$ & 0.001 & 0.005 & 0.842 \\
\hline & & & 0.048 & & & 0.663 \\
\hline Coping: avoiding $(7-26) \ddagger$ & 0.064 & 0.032 & 0.156 & 0.002 & 0.005 & 0.533 \\
\hline Coping: social support seeking $(6-24) \ddagger$ & -0.040 & 0.028 & & -0.003 & 0.004 & \\
\hline Coping: palliative $(6-22) \ddagger$ & -0.025 & 0.035 & 0.478 & 0.001 & 0.005 & 0.864 \\
\hline Coping: emotions $(3-12) \ddagger$ & -0.052 & 0.051 & 0.311 & 0.003 & 0.009 & 0.747 \\
\hline Coping: optimistic $(4-16) \ddagger$ & -0.046 & 0.039 & $<0.001$ & -0.002 & 0.007 & 0.436 \\
\hline Social support: emotional $(0-30) \ddagger$ & -0.064 & 0.018 & 0018 & -0.002 & 0.002 & 0082 \\
\hline Social support: instrumental $(0-24) \ddagger$ & -0.057 & 0.024 & $\begin{array}{l}0.018 \\
<0.001\end{array}$ & -0.000 & 0.003 & $\begin{array}{l}0.982 \\
0.318\end{array}$ \\
\hline Neuroticism $(0-12) \ddagger$ & 0.133 & 0.035 & & -0.004 & 0.004 & 016 \\
\hline Locus of control $(12-55) \ddagger$ & 0.054 & 0.014 & $<0.001$ & 0.003 & 0.002 & 0.165 \\
\hline
\end{tabular}

*Adjusted for age, gender and (other) chronic disease by severity category in 1991, and year of measurement (1991-1997). †Adjusted for age, gender and (other) chronic disease by severity category in 1991, year of measurement (1991-1997), and the interaction between the determinant of interest and age. $\neq$ Scale length.

example, one extra longlasting difficulty (measured with a list of 12 items) is associated with a 0.238 point higher OECD score. In the longitudinal change model, the variable coming closest to borderline statistical significance is locus of control: there is some indication that an external locus of control is associated with a marginally faster increase of the OECD score as compared with an internal locus.

\section{Discussion}

Our results suggest that among chronically ill persons the prevalence and severity of disabilities depends on a wide range of "extraneous" factors. With a repeated prevalence model in which we controlled for type and severity of chronic disease, we found strong associations between sociodemographic factors, health related behaviours, living and working conditions, and psychosocial factors on the one hand and the OECD score on the other hand. Quite clearly, these cross sectional associations must have originated at some point in time, but in the six year period covered by the longitudinal change model we only witnessed some of these processes. We found indications of varying strengths that marital status, degree of urbanisation, household income, smoking, alcohol consumption, unemployment, and locus of control are predictors of change in physical functioning, but only in the case of household income and alcohol consumption did the overall tests reach conventional levels of statistical significance.

Our study suffers from a number of limitations, which we will briefly discuss:

(1) Our study is based on a population sample of chronically ill persons, and although this increases the external validity of the study, it also implies that average severity is likely to be lower than in samples recruited in, for example, health care institutions. The fact that the total response at baseline is low, with disabled persons being more likely to be nonresponders, may further contribute to the low prevalence of severe disabilities. This low severity is reflected in the fact that the average OECD score in our study population is around 10 - that is, only two points above the minimum value. With such a low prevalence of disability, the effects of determinants, particularly on changes in disability, may be difficult to detect. This will even more be the case when the dependent variable is measured on an absolute scale, as we did-given the low average level of disability, absolute changes can only be even smaller. We would also like to note the fact that we have used a continuous score to summarise the OECD indicator. This is a rather crude measure that may conceal changes for specific aspects. Perhaps this partly explains the lack of associations between determinants and changes in disability in our study. Other reasons for not finding more "longitudinal" associations may be small sample size and short length of follow up (only six years, while the cross sectional associations were based on an age range of 60 years).

(2) Our study is entirely based on self reports. In this population-based study, it was impossible for budgetary reasons to include objective measurements of disease, disability and/or determinants. Although we used validated questionnaires where available, the use of self reports may have lead to a higher degree of (non-) differential misclassification. One indication is that neuroticism, which is associated with negative reporting tendencies, is also associated with the prevalence of disabilities (table 6 ). The results obtained in this study should therefore be taken as indications to be confirmed in further studies that, perhaps on a smaller scale, should use more optimal measurement strategies, such as physical performance measures based on the observation of a subject's performance of standardised tasks. ${ }^{25}$ 
(3) During the follow up period of our study, considerable attrition has occurred (table 1). One of the advantages of using GEE analysis is that we were not forced to limit the analysis to respondents with complete follow up, but could include in the analysis all those who participated at baseline, regardless of the number of measurements available. Of course, missing observations could still bias the results, particularly if associations between determinants and disability would be different between missing respondents/measurements than for the observations included in the analysis. One of the causes of attrition is death, which could be seen as an extreme form of disability and is associated with many of the determinants included in the analysis. It is necessary, therefore, to qualify the results by acknowledging that the reported associations probably only are valid conditional upon survival.

(3) The analyses reported in this paper are essentially univariate. We did control for a number of possible confounding variables, including age and chronic disease (but excluding other diseases, than the four selected conditions), however, the associations between each of the determinants of interest and disability were not mutually controlled. This is in line with the aims of the analysis, which were mainly exploratory, and is also related to the fact that truely multivariate models, particularly multivariate "longitudinal change" models, would have become very complex. Nevertheless, further studies focusing on a smaller number of possible determinants should consider multivariate analyses in order to discover if the associations reported in this paper are mutually independent.

Despite these limitations, our results indicate that levels and changes of physical functioning among chronically ill persons are partly determined by factors external to the disease process itself. These results largely confirm what others have reported before us, ${ }^{25}{ }^{26}$ but our study is characterised by some methodological refinements that have not frequently been achieved before. Firstly, not all previous studies have adequately controlled for type and severity of chronic disease. Secondly, not all previous studies have followed the same analytical approach, in which longitudinal change is clearly separated from cross sectional differences. By using unconditional regression models - that is, by not conditioning on the first measurement - we have also more effectively avoided regression to the mean than many previous studies. ${ }^{27} 28$

Because we have included such a wide range of possible determinants, our results enable us to compare and relate different (types of) determinants. One of our most striking findings relates to the importance of household income: this is not only a powerful predictor of levels of disability, but also one of the most important predictors of change in physical functioning: more important than the other two indicators of socioeconomic status (level of education and occupational class), and more important than gender and marital status, which have in previous studies been found to
KEY POINTS

- Little is known about factors not directly related to severity of disease that influence the occurrence of disability among chronically ill persons.

- We assessed the effect of sociodemographic factors, health related behaviour, structural living conditions, and psychosocial factors on levels and changes of physical functioning among chronically ill persons.

- Strong associations were found between most of the determinants and the prevalence of disabilities.

- Predictors of unfavourable changes in physical functioning were low income and excessive alcohol consumption.

- Reduction of the prevalence of disability in the population not only depends on medical interventions.

be important predictors of change in physical functioning. ${ }^{2-10}$ In a country like the Netherlands, which is characterised by relatively small income inequalities and a general lack of financial barriers to health care utilisation, this is a remarkable finding. Our other results suggest that the association between household income and change in physical functioning can at least partly be explained by higher rates of smoking and external locus of control among those with a low household income. Other analyses within the GLOBE study have shown that these variables are strongly associated with indicators of socioeconomic status: persons with a lower income smoke more and more often have an external locus of control. ${ }^{29}{ }^{30}$ The results reported in this paper show that these variables are also associated with unfavourable changes in physical functioning, suggesting that the effect of low income on physical functioning is at least partly mediated by smoking and external locus of control. Whether these effects are themselves mediated by unfavourable changes in disease severity, or operate entirely independently from changes in disease severity over time, is difficult to say. Our analyses only controlled for disease severity at baseline, and this does not preclude the possibility that the factors that then were still external to the disease process, actually exerted their effects through later changes in disease severity.

In conclusion, factors other than characteristics of the underlying disease have an important influence on levels and changes of physical functioning among chronically ill persons. Compression of morbidity not only depends on medical interventions, but may also require social interventions, health education, and psychological interventions among chronically ill persons.

We would like to thank Roel Faber and Ilse Oonk for maintaining the database of our study.

Funding: the Globe study is financially supported by the Prevention Fund, and the Dutch Ministry of Public Health, Prevention Fund, and the Dutch Ministry of Public Health,
Welfare and Sports. The study is performed by the Department Welfare and Sports. The study is performed by the Department
of Public Health of Erasmus University Rotterdam, in collaboration with the Public Health services of the city of Eindhoven 
and the region of South-East Brabant. Dr Nusselder is supported by a grant from the Netherlands Organisation for Scientific Research, research programme "Care for chronic diseased" ("ZOB").

Conflicts of interest: none.

\section{Appendix OECD Long term disability questionnaire}

1 Can you hear what is said in a normal conversation with one other person?

(with a hearing aid if you usually wear one).

2 Can you hear what is said in a normal conversation with at least three other persons?

(with a hearing aid if you usually wear one).

3 Is your eyesight good enough to read ordinary newspaper print? (with glasses if usually worn).

4 Is your eyesight good enough to see the face of someone from four metres? (with glasses if usually worn).

5 Can you both bite and chew on hard food? (for example a firm apple)

6 Can you carry an object of 5 kilos for 10 metres ?

7 Can you (when standing), bend down and pick up a shoe from the floor?

8 Can you walk 400 metres without resting?

The possible answers were:

(a) yes, without difficulty

(b) yes, with some difficulty

(c) yes, with much difficulty

(d) no, I cannot do this

1 Fries JF. Aging, natural death and the compression of morbidity. N Engl f Med 1980;303:130-5.

2 Crimmins EM, Saito Y. Getting better and getting worse; Crimmins EM, Saito Y. Getting better and getting worse; transitions in functional status among
fournal of Aging and Health 1993;5:3-36.

3 Rogers RG, Rogers A, Belanger A. Disability-free life among the elderly in the United States. Fournal of Aging and Health 1992;4:19-42.

4 Avlund K, Davidsen M, Schultz-Larsen K. Changes in functional ability from ages 70-75. A Danish longitudinal study. Fournal of Aging and Health 1995;7:254-82.

5 Strawbridge WJ, Cohen RD, Shema SJ, et al. Succesful aging: predictors and associated activities. Am f Epidemio 1996;144:135-41.

6 Hubert HB, Fries JF. Predictors of physical disability after age 50. Six-year longitudinal study in a runners club and a university population. Ann Epidemiol 1994;4:285-94.

7 Hubert HB, Bloch DA, Fries JF. Risk factors for physical disability in an aging cohort: the NHANES I epidemiologic

8 Camacho TC, Strawbridge WJ, Cohen RD, et al. Functional ability in the oldest old. Cumulative impact of risk factors from the preceding two decades. Fournal of Aging and from the preceding two

9 Guralnik JM, LaCroix AZ, Abbott RD, et al. Maintaining mobility in late life. I. Demographic characteristics and chronic conditions. Am f Epidemiol 1993;137:845-57.
10 Amaducci L, Maggi S, Langlois J, et al. Education and the risk of physical disability and mortality among men and women aged 65 to 84 : The Italian longitudinal study on aging. F Gerontol 1998;53A:M484-90.

11 Breslow L, Breslow N. Health practices and disability: some evidence from Alameda County. Prev Med 1993;22:86-95.

12 LaCroix AZ, Guralnik JM, Berkman LF, et al. Maintaining mobility in late life. II. Smoking, alcohol consumption, physical activity, and body mass index. Am 7 Epidemiol 1993;137:858-68.

13 Vita AJ, Terry RB, Hubert HB, et al. Aging, health risks, and cumulative disability. N Engl F Med 1998;338:1035-41.

14 Mendes de Leon CF, Seeman TE, Baker DI, et al. Self-efficacy, physical decline, and change in functioning in community-living elders: a prospective study. 7 Gerontol 1996;51B:S183-90.

15 Mackenbach JP, Mheen $\mathrm{H}$ van de, Stronks K. A prospective cohort study investigating the explanation of socioeconomic inequalities in health in the Netherlands. Soc Sci Med 1994;38:299-308.

$16 \mathrm{McWhinnie} \mathrm{JR.} \mathrm{Disability} \mathrm{assessment} \mathrm{in} \mathrm{population} \mathrm{surveys:}$ Results of the O.E.C.D. common development effort. Rev Epidemiol Santé Publique 1981;29:413-19.

17 Sonsbeek JLA van. Gezondheidsenquêtes: methodische en inhoudelijke aspecten van de OESO-indicator betreffende angdurige beperkingen in het lichamelijk functioneren. Maandbericht Gezondheidsstatistiek 1988;7:4-17.

18 Lende $\mathrm{R}$ van der, Jansen-Koster EJ, Knijpstra S, et al. Definitie van CARA in epidemiologie en preventie. Ned Tijdschr Geneeskd 1975;119:1975-87.

19 Baart A. De oude havenwerker. Aspecten van zijn cardiorespiratoire conditie. [Thesis.] Rotterdam: Erasmus University Rotterdam, 1973.

20 Rose G, Blackburn H. Cardiovascular survey methods. WHO Monograph 1968;56:1-88.

21 Pennings-van der Eerden L. Zelfzorg en motivatie van patiënten met diabetes mellitus. Utrecht: Vakgroep Algemene Gezondheidszorg en Epidemiologie, Rijksuniversiteit Utrecht, 1984.

22 Kuorinka I, Jonsson B, Kilbom A, et al. Standardised Nordic questionnaires for the analysis of musculoskeletal symptoms. Appl Ergon 1987;18:233-7.

23 Anonymous. Vragenlijst ERGO. Rotterdam: Instituut Epidemiologie \& Biostatistiek, Erasmus Universiteit Rotterdam, 1989.

24 Liang K-Y, Zeger SL. Longitudinal data analysis using generalized linear models. Biometrika 1986;73:13-22.

25 Guralnik JM, Fried LP, Salive ME. Disability as a public health outcome in the aging population. Anпu Rev Public Health 1996;17:25-46.

26 Kaplan GA. Maintenance of functioning in the elderly. Ann Epidemiol 1992;2:813-22.

27 Lord FM. A paradox in the interpretation of group comparisons. Psychol Bull 1967;68:304-5.

28 Lord FM. Statistical adjustments when comparing preexisting groups. Psychol Bull 1969;72:336-7.

29 Schrijvers CTM, Stronks K, Mheen H van de, et al. Explaining educational differences in mortality: the role of behavioural and material factors. Am $\mathcal{F}$ Publ Health 1999;89:535-40.

30 Bosma H, Schrijvers CTM, Mackenbach JP. Socioeconomic inequalities in mortality and importance of perceived control: cohort study. BMF 1999;319:1469-70. 